\title{
Article
}

\section{Student Use of Out-of-Class Study Groups in an Introductory Undergraduate Biology Course}

\author{
Stephen M. Rybczynski* and Elisabeth E. Schussler ${ }^{\dagger}$
}

\author{
*Department of Botany, Miami University, Oxford, OH 45056; and ${ }^{\dagger}$ Department of Ecology \\ and Evolutionary Biology, University of Tennessee, Knoxville, TN 37996-1610
}

Submitted April 15, 2010; Revised September 29, 2010; Accepted October 4, 2010

Monitoring Editor: Diane K. O’Dowd

\begin{abstract}
Self-formed out-of-class study groups may benefit student learning; however, few researchers have quantified the relationship between study group use and achievement or described changes in study group usage patterns over a semester. We related study group use to performance on content exams, explored patterns of study group use, and qualitatively described student perceptions of study groups. A pre- and posttest were used to measure student content knowledge. Internet-based surveys were used to collect quantitative data on exam performance and qualitative data on study group usage trends and student perceptions of study groups. No relationship was found between gains in content knowledge and study group use. Students who participated in study groups did, however, believe they were beneficial. Four patterns of study group use were identified: students either always $(14 \%)$ or never $(55 \%)$ used study groups, tried but quit using them $(22 \%)$, or utilized study groups only late in the semester (9\%). Thematic analysis revealed preconceptions and in-class experiences influence student decisions to utilize study groups. We conclude that students require guidance in the successful use of study groups. Instructors can help students maximize study group success by making students aware of potential group composition problems, helping students choose group members who are compatible, and providing students materials on which to focus their study efforts.
\end{abstract}

\section{INTRODUCTION}

Cooperative learning strategies are increasingly being employed by college biology instructors both in and out of the classroom (Burrowes, 2003; Maloof and White, 2005; Tessier, 2007).Cooperative learning can be defined as an instructional strategy that utilizes small groups of students working together to achieve a common goal (Johnson and Johnson, 1999). This form of learning differs from traditional learning strategies that involve students working on their own (individualistic) or competing against their peers (competitive) in an organized way (Johnson et al., 1998). According to these authors, there are five fundamental

DOI: $10.1187 /$ cbe.10-04-0060

Address correspondence to: Stephen M. Rybczynski (rybczysm@ muohio.edu).

(C) 2011 S. M. Rybczynski and E. E. Schussler. CBE—Life Sciences Education (C) 2011 The American Society for Cell Biology. This article is distributed by The American Society for Cell Biology under license from the author(s). It is available to the public under an AttributionNoncommercial-Share Alike 3.0 Unported Creative Commons License (http://creativecommons.org/licenses/by-nc-sa/3.0).

"ASCB ${ }^{\circledR}$ " and "The American Society for Cell Biology ${ }^{\circledR}$ " are registered trademarks of The American Society for Cell Biology. elements of cooperative learning: 1) students' success must be linked with the success of their group members; 2) students must actively work together; 3 ) each member, as well as the group as a whole, must be accountable for his or her work; 4) students must learn academic content as well as teamwork skills; and 5) students must evaluate their groups' progress. Cooperative groups can vary in purpose, duration, and composition, and three basic types have been defined: base groups, formal groups, and informal groups (Johnson et al., 1991). Base groups are long-term groups, possibly lasting the duration of a course, that consist of the same members meeting routinely; these function as a learning support group. Formal groups meet to work on a specific task or project and exist until the project is completed (days or weeks). Informal groups are relatively brief in duration, work on short-term assignments such as answering a question in class, and are often organized and managed by instructors within the classroom as part of the curriculum. In some cases, students may spontaneously and voluntarily form groups outside of class (Tang, 1993), and these out-of-class study groups are generally considered informal (Barkley et al., 2005).

Cooperative group work within the classroom has been shown to increase student achievement as well as promote a more positive attitude toward the subject being studied 
(Springer et al., 1999). Additionally, students have reported a more positive learning experience in cooperative settings compared with traditional lectures (Peterson and Miller, 2004). A number of cooperative learning models have been developed and implemented in a wide range of subjects and grade levels (Slavin, 1995), including college-level biology courses. Tessier (2007) describes a program in which students worked in small groups to complete in-class assignments by teaching designated concepts to one another. On the exams, students correctly answered a greater proportion of questions covering peer-taught material compared with the material presented in traditional lecture. Similarly, Burrowes (2003) found that students using cooperative learning strategies scored significantly higher on exams than students taught using traditional lecture.

While using cooperative groups within the classroom has the potential to enhance student learning, instructors must manage several aspects of the groups (i.e., group composition and size) to maximize the likelihood of a successful experience. For example, when forming student groups, it is generally accepted that groups should be heterogeneous (Wood, 2009) and assigned by the instructor (as opposed to self-formed) in order to prevent students from slacking off and becoming "free riders" (Crowe and Hill, 2006). Decisions regarding the size of the group should take into account the learning objective; some researchers have advocated groups of two to three students while others suggest up to five or six students in a group (Barkley et al., 2005).

Some instructors choose not to incorporate cooperative learning strategies as part of their in-class activities for a variety of reasons, including difficulties grading student group work and not knowing how to implement study groups (Herried, 1998). For instructors who wish to incorporate cooperative learning but are uncomfortable making it mandatory, one alternative is to encourage students to study in small groups outside of class (Light, 2001).

Out-of-class study groups are self-formed, informal study groups that meet outside of class to study course material for quizzes and exams. These groups are not typically directed by the instructor or involved in working on graded assignments. In a study of over 500 Harvard undergraduates, students who participated in such out-of-class study groups for science classes were more likely to take additional science classes than students who studied only individually (Light, 2001). It has been proposed that this type of out-of-class group study has the potential to increase the academic performance of students as well as improve students' confidence, interpersonal communication skills, and diversity awareness (Petress, 2004), especially in introductory biology classes where attrition and failure rates are relatively high (Seymour and Hewitt, 1997). In a study of minority students taking calculus at the University of California, Berkeley, it was concluded that participation in out-of-class study groups was the single most important factor in the differential success of Chinese students who used such groups and AfricanAmerican students who did not (Treisman, 1992).

Because out-of-class study groups are rarely monitored by instructors, there is little published research regarding whether or not students benefit from participating in the groups (Slavin, 1996; but see Sokolove and Marbach-Ad, 1999; Sokolove et al., 2003), how or why study groups form, whether students' study group usage changes throughout a semester, or student perceptions of their study group experiences. Our first objective was to test the hypothesis that study group usage is related to student performance on content exams. We predicted that students who use study groups would score higher on content exams than those students who do not use study groups. Our second objective was to describe how study group usage patterns change over the course of a semester. Finally, our third objective was to explain patterns of study group usage by identifying student perceptions of study groups. These included a description of the students' presemester preconceptions regarding study groups, their study habits, and reasons why they ultimately chose to use or reject study groups.

\section{METHODS}

\section{Subject Population and Course Description}

Student participants were recruited from an introductory biology course at a midsized, midwestern university during the Fall 2007 semester. This course is a 4-credit lecture and laboratory class, with an annual enrollment of approximately 700 mostly science major students. The class is delivered in three lecture sections of approximately 180-250 students each (plus one smaller section of Honors, which was not included in the study) and utilizes primarily a lecture format. The course is team taught, and each section is instructed by three different professors; however, there were only eight total instructors because one of them taught two sections. Topics covered in the course include, but are not limited to, evolution, ecology, genetics, and the diversity of life.

As part of the study, the first author observed the first 2 weeks of class in each of the three lecture sections. In all sections, the use of out-of-class study groups (henceforth, "study groups") was encouraged, but no information on how to use study groups effectively was provided to the students. This encouragement occurred during a review of the course syllabus, at which time instructors in all sections told their students that forming groups outside of class to prepare for exams was a useful study technique. The first day of class was the only time during the semester that the instructors formally and in front of the class discussed the use of cooperative study groups; however, some lecture sections set up online discussion boards by dorm to encourage the formation of study groups. At no time were cooperative learning strategies explicitly modeled in any of the sections. For the most part, all three sections were uniform in their level of encouragement regarding the use of study groups even though a standardized script was not used.

\section{Quantitative Pre- and Posttests of Content Knowledge}

A multiple-choice test of biological content knowledge was administered to all lecture sections at the beginning and end of the semester as a measure of student gains in content knowledge. This content exam was part of the research study and not for a grade in the lecture class; therefore, students volunteered to participate without incentive. Participants took the pretest on the first day of lab and the posttest on the last day of lecture in their respective sections. The questions were provided by the instructors of the course and reflected the major content areas of the course (i.e., ecology, evolution, 
etc.). The same 25 questions were on the pre- and posttest; however, 8 of the questions were inadvertently included on some of the lecture exams or quizzes, so only 17 questions were used in the analysis.

\section{Internet-Based Surveys}

Over the course of the semester, four surveys were administered to students in the class. Both qualitative and quantitative data, including self-reported scores on exams, were collected through the use of multiple-response (forced-choice), Likert scale (1-5), and open-ended questions. Surveys were constructed using SurveyMonkey, an Internet-based survey application, and sent via email to all students enrolled in the course. Participants were informed of these surveys by the first author verbally at the beginning of class the day before the survey email was sent; no incentive for participation was provided. The surveys were distributed the first week of class and immediately following the posting of grades for each of the three midsemester lecture exams. Each survey contained some unique questions and some that were the same as in previous surveys, and each took participants less than $10 \mathrm{~min}$ to complete. All procedures for this research were approved by the university's Institutional Review Board for Human Subjects Research.

To link participant responses on the surveys and pre-post content tests, participants provided a unique alphanumeric identifier at the beginning of each instrument. At the end of the semester, it was found that only 56 respondents completed all four surveys, and only 36 of these also completed the pre- and posttest of content knowledge. Therefore, instead of treating the data longitudinally, all data collected for each survey were used in the data analysis in order to maximize statistical power. The only exceptions were 1) the mixed-model analysis of study group usage and exam score and 2) the analysis of covariance (ANCOVA) of the pre- and posttest scores and patterns of study group usage.

Demographic data on participants were collected using survey 1 (see Table 1 for a summary of survey questions). Data on student study group usage and performance on inclass exams were collected with surveys $2-4$. Because study group usage data collected with survey 3 proved to be redundant with information collected with survey 4 and had a substantially smaller number of participants, these data are not presented. Student preconceptions of study groups were assessed with survey 1 . Study group characteristics were assessed with surveys 2 and 4 , as were perceptions of benefit. Reasons why students did or did not participate in study groups were collected with survey 2 .

\section{Data Analysis}

An ANCOVA was used to determine differences in student achievement as measured by the content knowledge pre- and posttest. Posttest score was used as the dependent variable with pretest score as the covariate, and study group usage and lecture section were treated as fixed effects. A maximumlikelihood mixed model was used to determine differences in lecture exam performance among students who participated in study groups and those who did not. In this model, student exam (1 and 3) grades and study group usage on each exam were matched for each individual $(n=36)$ and treated as fixed effects while individual participants were
Table 1. Summary of survey questions on surveys 1,2 , and 4

Survey 1 1. Demographics, including lecture section, gender, year in school, and major

2. Have you ever voluntarily formed or joined an out-of-class study group for a science class?

3. "I usually prefer to study for exams on my own." (Likert-response question)

4. "If I knew that a particular group of students was productive studying together, I would be willing to participate in that study group." (Likert-response question)

5. "Do you have any thoughts regarding study groups that you would be willing to share?" (Open-response question)

Survey 2 1. Did you study for the first exam in a small group at any time?

2. What grade did you receive on the first exam?

3. How many people were typically in your study group for the first exam?

4. Which of the following activities did your study group participate in? (Forced-choice response; see Results for responses)

5. Do you feel studying in a group helped your grade on this last exam?

6. "I would appreciate specific instructions on how to run a productive study group." (Likert-response question)

7. What prompted you to form/join a study group to prepare for the last exam? (Open-response question)

8. Is there any particular reason you decided not to study with a group that you would be willing to share? (Open-response question)

Survey 4 1. For which of the exams did you study with others in a small group of 2 or more people? Please select all that apply: A) exams 1 or $2, \mathrm{~B})$ exam 3, or C) none of the exams.

2. What grade did you receive on the third (most recent) exam?

3. Which of the following statements BEST describes your current attitude toward studying with others for exams? (Forced-choice response; see Results for responses)

4. What was (or were) the most challenging aspect(s) of participating in an out-of-class study group? (Forced-choice response; see Results for responses)

5. "I usually prefer to study for exams on my own." (Likert-response question)

6. "If I knew that a particular group of students was productive studying together, I would be willing to participate in that study group." (Likert-response question)

treated as a random effect. Although student demographics including gender, year in school, and major were collected, low sample sizes precluded our ability to analyze these data as part of either the mixed model or ANCOVA. Therefore, study group usage was the only grouping variable used in the mixed model, and study group usage and lecture section were used in the ANCOVA. Results for forced-choice questions are reported as percentages. For Likert-style survey responses, Student's $t$ test was used to identify significant changes in responses between matched participants on surveys. Open responses were qualitatively analyzed for themes using grounded theory analysis as described by Corbin and 
Strauss (1990), whereby responses were repeatedly read and emergent themes were identified, described, and supported with student quotations.

\section{RESULTS}

\section{Student Demographics}

On the first survey, 246 students reported their gender, year in school, major, where they took their last biology class, their grade in that class, and whether or not they had voluntarily formed study groups in the past. About 35\% $(n=87)$ of the respondents were male and $65 \%(n=159)$ were female as compared with the actual course population of $255(46 \%)$ males and 294 (54\%) females. Most respondents were in their first year of college $(73 \% ; n=179)$, while $18 \%(n=45)$ were second-year students and $9 \%(n=21)$ were in their third year or older. For $85 \%(n=204)$ of respondents, their last biology class was in high school, and 93\% $(n=222)$ had received either an " $\mathrm{A}$ " or a " $\mathrm{B}$ " in that class. Prior to the study, $59 \%(n=142)$ of respondents had voluntarily formed or joined a study group with their peers to prepare for a science class. There were fewer respondents on surveys 2 $(n=115)$ and $4(n=121)$, although the demographics of students responding to these surveys were similar to those of survey 1, and all demographic groups were represented in all statistical analyses.

\section{Study Group Usage and Student Performance on Content Exams}

There were no significant differences in lecture exam scores (exams 1 and 3 ) between participants who used study groups and those who did not use such groups (Figure 1) as revealed by mixed-model analysis $(n=36, F=0.402, p=0.53)$. The actual exam scores (mean $\pm 1 \mathrm{SD}$ ) for all three lecture sections $(n=563)$ were $75.5 \% \pm 10.1$ for exam 1 and $73.4 \% \pm$ 14.1 for exam 3. Only 36 participants completed surveys 1 , 2 , and 4 and self-reported their exam grades in the form of a percentage. Of these participants, 28 were female and 8 were male. On exam 1, participants who used a study group $(n=12)$ scored $77.0 \% \pm 7.6$ while those who did not use a

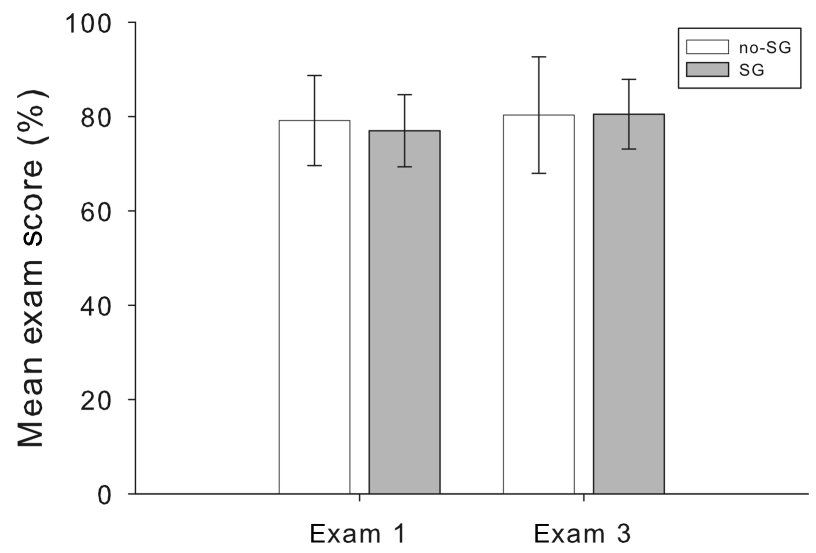

Figure 1. Mean exam scores for students who participated in a study group (SG) and those who did not participate in a study group (no-SG) on exam 1 (SG: $n=11$; no-SG: $n=24$ ) and exam 3 (SG: $n=$ 8; no-SG: $n=28$ ). Error bars represent 1 standard deviation.

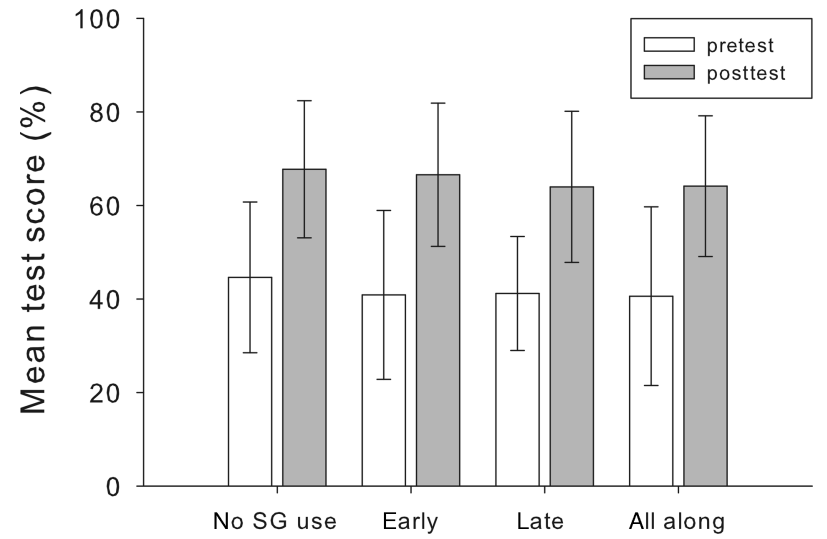

Figure 2. Mean pretest and posttest scores for students who did not participate in a study group (no SG use: $n=41$ ), students who participated in a study group early in the semester but quit before the end of the course (early: $n=19$ ), students who studied alone only in the beginning of the semester but used a study group toward the end of the course (late: $n=8$ ), and students who used study groups throughout the semester (all along: $n=10$ ). Error bars represent 1 standard deviation.

study group $(n=24)$ scored $79.2 \% \pm 9.5$. On exam 3 , participants who used a study group $(n=8)$ scored $80.3 \% \pm 12.3$ while those who did not use a study group $(n=28)$ scored $80.5 \% \pm 7.4$.

There were likewise no significant differences in pre-post content test scores found among users or nonusers of study groups using an ANCOVA model $(n=78, F=0.028, p=0.99)$ (Figure 2). Posttest scores (mean $\pm 1 \mathrm{SD}$ ) were $67.7 \% \pm 14.7$ $(n=41)$ for students who never used study groups, $66.6 \% \pm$ $15.3(n=19)$ for those who used a study group only early in the semester (first or second exam), 64.0\% $\pm 16.2(n=8)$ for those who used a study group only late in the semester (third exam), and 64.1\% $\pm 15.0(n=10)$ for those who used a study group for all in-class exams. The model also revealed no differences in pre- or posttest scores among lecture sections $(F=0.955, p=0.39)$. The only significant predictor of posttest score was the pretest score, which was correlated with the posttest score $(F=6.70, p=0.01)$.

\section{Student Preconceptions of Study Groups}

Student preconceptions of study groups were obtained from 62 participants on the first survey using the open-response question "Do you have any comments about study groups you would like to share?" Thematic analysis revealed six recurrent themes among the responses centered on either the utility or effectiveness of study groups, and many of these themes were interrelated.

Group Composition Is Important. The predominant theme found in student responses was the idea of group composition $(n=23)$. Student responses often expressed that who the group consists of influences the usefulness, effectiveness, or function of the group. While students had different ideas of what made a good group member (i.e., friends or acquaintances vs. strangers), their ability or "level" of knowledge and their willingness to participate were often cited. For example, one respondent stated, "I love when I get in a group with students similar to my learning level, therefore it's not only me participating but everyone." Another said, "I just want to 
know that I'm working with people who know what they are doing and are willing to work hard." In addition to the characteristics of the individual group members, some respondents said that the number of students in the group is important. One student said, "I feel study groups above three members in size start to decline in usefulness." Although students might not have agreed on the ideal group size, no comments suggested that the composition of the group is unimportant.

Equal Commitment from All Group Members. Many participants indicated that all group members need to contribute and participate equally for study groups to be effective $(n=$ 15). Interestingly, students who viewed study groups favorably and unfavorably made statements that fell into this theme. For example, one student said, "When the work is divided among the members of the group and everyone does their job, then study groups are beneficial." Conversely, another said, "The group situation creates stress because you have to depend on others for an equal contribution and that doesn't always happen." There were no responses that suggested it does not matter whether everyone in the group contributes.

Lack of Productivity Is a Problem. Participants indicated that a lack of productivity is a problem in study groups $(n=$ 13). Many responses indicated that students expected to get some benefit from working in a study group and a lack of productivity led to unfavorable attitudes toward study groups. For example, one student said, "I dislike study groups when the majority of the time is spent talking and nothing productive is done." Other students described how study groups are less productive than individual studying when they said, "I feel that most study groups get less done than working on your own." While opinions differed on whether groups consisting of "people I get along with" or "people less familiar with each other" were more productive, it was clear that students felt that group composition can influence productivity.

Study Groups Are Distracting and Lack Focus. There was a perception of study groups being distracting or that students have problems focusing in them $(n=12)$. Some stated this outright while others elaborated on reasons for study groups being distracting. For example, one respondent said, "One student goofing off or not focusing can cause the whole group to lose track of where it is in the studying process." Another said, "When you gather that many college or high school students together, the possibility for slacking off and not focusing as much becomes much greater." All responses in this theme described distraction and lack of focus as either a challenge to overcome or a reason for rejecting the use of study groups.

Social Learning Has Inherent Value. Some students reported that studying in a social setting is beneficial $(n=15)$. Statements that conveyed this theme described a belief that group interaction promotes learning better than studying alone. One student typified this sentiment by saying, "When the members of the group have actively participated, the results for each member were much better than if each member would have studied on his own." Another student described why this social interaction is helpful when she said, "They help me because when I take a test and a question comes up I can sometimes recall the answer by remembering what others said during the study group.... I remember their face and what they said." These responses generally did not mention negative aspects of study group usage and made no references to group composition.

Preference for Individual Learning. A small proportion of the respondents indicated that they prefer to study on their own $(n=5)$. Several stated that they are more productive studying individually compared with study groups. For example, one student said, "I feel that most study groups get less done than working on your own." Others indicated a definite dislike of study groups for these reasons by saying, "I don't like [study groups] because I like to work at my own pace and cover the material that I feel I need to go over." None of these individuals mentioned any perceived benefits to studying in groups.

\section{Reasons Why Students Choose to Participate or Not Participate in Study Groups}

On the second survey, students were asked why they did or did not participate in a study group. Those individuals who had participated in a study group prior to the first exam were asked, "What prompted you to form/join a study group to prepare for the last exam?" Individuals who had not participated in a study group were asked, "Is there any particular reason you decided not to study with a study group that you would be willing to share?" A total of 27 individuals elaborated on why they had participated in a study group while 51 individuals described why they chose not to participate in a group.

Thematic analysis of reasons why students did use study groups revealed two dominant themes. These were 1) a desire for help or clarification and 2) a perceived benefit of social learning. There was virtually no overlap of themes among individual responses.

Desire for Help or Clarification. Students reported that a need to clarify the course material was a reason for participating in a study group $(n=10)$. One student stated, "I had questions about some of the stuff on the study guide so I asked some people in my dorm who have the same class and the group just kind of started." These students did not form a study group for its own sake. They developed a need for additional help at some point in the semester and believed a study group was the solution.

Perceived Benefit of Social Learning. The previously identified theme of perceiving a benefit from social learning was also cited as a reason for participating in a study group $(n=$ 6). One student described this by saying, "I knew it would be beneficial to me to explain ideas to other people and to have my peers help me with any problems I had." Other students simply desired a venue for dialog and made comments such as "... sometimes hearing other people talk is good because they might have picked up on subtle facts that I didn't hear." For these students, social interaction appeared to be critical to learning.

Students who did not participate in a study group for the first exam cited three principle reasons. These included 1) logistical difficulties, 2) study groups are distracting and lack focus, and 2) preference for individual learning. The latter two themes also appeared in the student preconception themes identified earlier. 
Logistical Difficulties. The most commonly cited reason why students did not use study groups were logistical difficulties such as lack of time and an inability to find a group $(n=21)$. For example, one student described, "I did not have time that week to study with anyone due to four papers, an exam in another class, and lab materials during that same week." Another student explained, "Tried to find a group; too hard to get in contact with or meet." For these students, any purported benefits of study group usage were eclipsed by the difficulty associated with forming or joining a group.

Study Groups Are Distracting and Lack Focus. Another theme that carried over from study group preconceptions was the idea that study groups are distracting and lack focus. One of these students said, "I learn better when I am not distracted. I need to be alone in a quiet environment, unless I come to material I still do not understand after studying on my own." These students found the risks of distraction outweighed the benefits of using the study group.

Preference for Individual Learning. We found that some individuals had a preference for studying alone, just as in student preconceptions of study groups. Some responses were succinct, such as "I like to study alone." There were also respondents who perceived that individual study is better or more efficient. One student stated, "I feel that I get more work done on my own." For these students, individual studying is simply more productive.

\section{Patterns of Study Group Usage}

Survey 1 gathered information regarding students' prior experiences with voluntary study groups before the semester began. Surveys 2 and 4 gathered information from students about their pattern of study group usage during the course. Because not all participants answered all survey questions, sample sizes are reported for each question.

A total of 95 participants responded to surveys 1 and 2 and provided usable data: 70 females and 25 males. Of these, 51 reported having used a voluntary study group prior to taking this course while 44 had not. A total of $37 \%$ of respondents $(n=19)$ who had prior study group experience used a study group for exam 1 , and $30 \%$ of respondents $(n=$ 13) without prior study group experience used study groups. Students who had previous experience using study groups before this course were no more likely to utilize study groups than students with no prior experience as revealed by chisquare contingency analysis $\left(n=95, \chi^{2}=0.63, p=0.96\right)$.

A total of 121 participants, 80 females and 41 males, responded to survey 4 . When asked about their pattern of study group usage over the semester, $54.5 \%$ of students $(n=66)$ reported having never participated in a study group. Students who used a study group early in the semester (for exams 1 or 2 ) and then stopped using them accounted for $22.3 \%$ of respondents $(n=27)$, and $9 \%(n=11)$ did not use a study group until the third lecture exam (exam 3 only). Only $14 \%$ of students $(n=17)$ used a study group throughout the semester.

\section{Student Reflections on Use of Study Groups}

Study Group Characteristics. The majority of students reported in survey $2(n=40)$ that their study groups for exam 1 were composed of only two or three members $(72.5 \%$; $n=29)$. Among students who reported using study groups for exam $1,98 \%(n=39)$ spent their time discussing or clarifying notes with group members, $68 \%(n=27)$ worked on problems or questions generated by the instructor, $62 \%$ ( $n=$ $25)$ discussed biology concepts or topics not specifically in the notes, $35 \%(n=14)$ worked on problems or questions generated by group members, and $25 \%(n=10)$ copied notes they had missed from group members. Of the students who reported studying for any exam with a study group (survey $4 ; n=77$ ), the most challenging aspect of working in a study group was "Deciding what to study and how to best go about it" $(63.6 \% ; n=49)$. "Different levels of preparedness among group members" was cited by $53.2 \%$ of respondents $(n=41)$, and "finding time to meet with people" was cited by $55.8 \%$ $(n=43)$. Only $27.3 \%$ of participants $(n=21)$ reported having problems with "meeting people with whom I can work well," and $16.9 \%(n=13)$ had problems "finding a place to meet with my group."

Perceptions of Benefit. Of those students who reported having participated in a study group for exam 1, 85\% (survey $2 ; n=115$ ) believed that "studying in a group helped [their] grade on this exam." A majority of participants (73.2\%) agreed with the statement "Participation in a study group runs the risk of spending my time less productively than I might spend it studying on my own." A majority of respondents on survey $4(n=121)$ who used a study group at some point in the semester had a positive experience $(89.7 \%)$. However, only $47.4 \%$ believed that it had helped their grade, while $42.3 \%$ said it did not help their grade.

We found a general trend of increasing negativity toward using study groups over the course of the semester with an increased desire for direction in their use. Student's $t$ test revealed a significant increase in agreement from survey 1 to survey 4 with the statement "I usually prefer to study for exams on my own" ( $n=94, t=3.13, p=0.001)$. There was also a significant decrease in agreement with the statement "If I knew that a particular group of students was productive studying together, I would be willing to participate in that study group" $(t=-4.86, p \leq 0.001)$. However, there was a significant increase in agreement from survey 2 to survey 4 with the statement "I would appreciate specific instructions on how to run a productive study group" $(n=67, t=2.01$, $p \leq 0.02)$.

\section{DISCUSSION}

\section{Study Group Usage and Exam Scores}

In this study, we found no relationship between student gains in content knowledge or exam performance and study group usage. Devoe et al. (2007) found similar results in a study of medical students at the University of New Mexico School of Medicine, where they found no differences between exam scores of those who used study groups and those who did not. In our investigation, participation in study groups may not have helped in terms of test scores but neither did it have a negative impact. This finding refutes the hypothesis that participation in poorly run (i.e., without proper guidance) study groups carries learning risks (Barkley et al., 2005). It is necessary, however, to view these results with caution due to our small sample size and slightly higher participant exam scores compared with the actual exam scores for the class as 


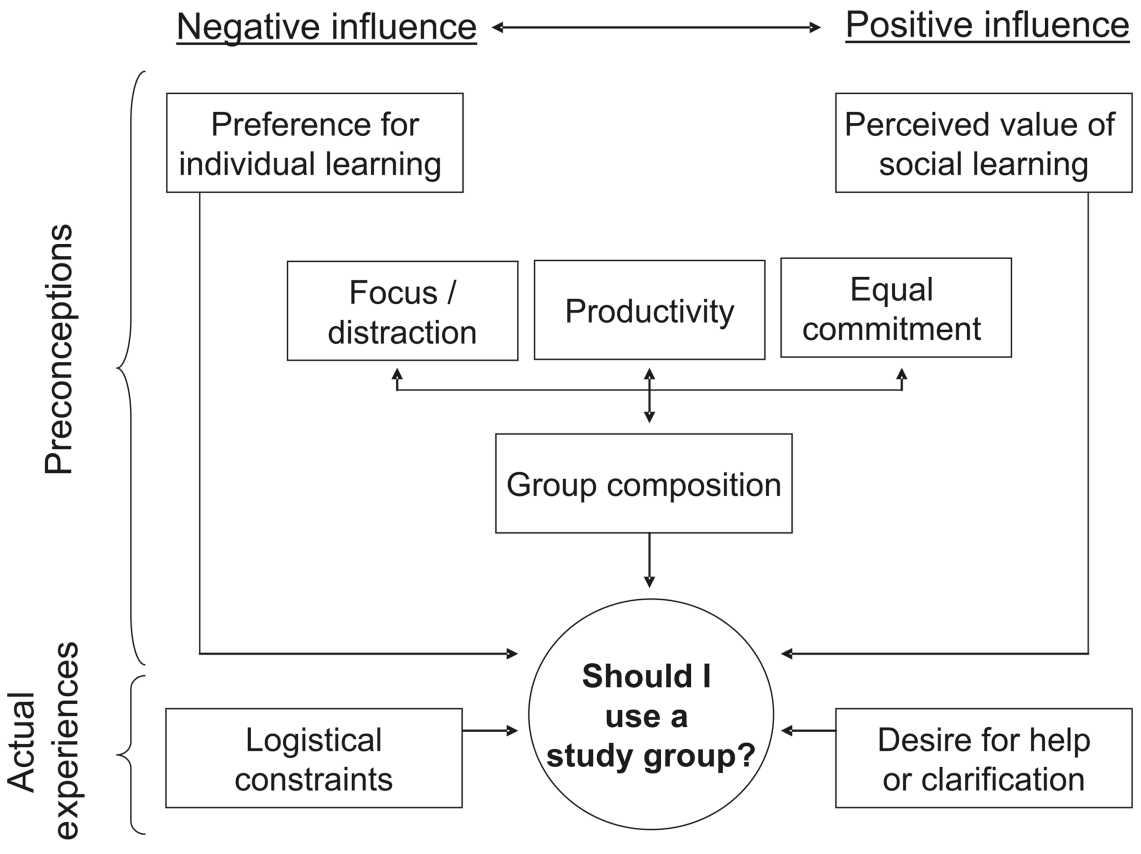

Figure 3. Model of factors that may influence student decision to participate in a study group. Factors that exerted a positive influence (i.e., cited by students likely to use a study group) on study group participation are located on the right side of the diagram while factors that exerted a negative influence (i.e., cited by students unlikely to use a study group) are located on the left of the diagram. Factors of mixed influence are located in the center. Factors based on student preconceptions are located in the upper portion of the diagram, and factors from students' actual experiences are located on the bottom of the diagram. a whole. Also, the gender ratio in our analyses was slightly skewed by the higher number of females among our participants; however, it has been previously observed that females are more likely than males to participate in human-subjects research at the university at which this study took place (E. Schussler, personal communication).

Investigations of in-class study group usage have yielded conflicting results regarding student achievement. Some studies have found significant increases in achievement between students who used groups and those who did not (Sokolove and Marbach-Ad, 1999; Burrowes, 2003; Maloof and White, 2005; Tessier, 2007). Conversely, Armstrong et al. (2007) found that differences in achievement were not significant between traditional lecture and cooperative learning treatments; however, students in the cooperative sections did have greater improvement in achievement over the course of the semester compared with those in the control group. It has been suggested that the benefits of study groups may extend beyond content gains as measured by test scores and may include increased engagement with the subject matter (Pukkila, 2004) and a shift in student in-class questions from lowerlevel (i.e., knowledge/clarification) to higher-level (i.e., application/synthesis) thinking (Ebert-May et al., 1997). This suggests that using exam scores as the only measure of student success may inhibit a thorough understanding of the full effects of study group usage and that other aspects of the students' experiences should be assessed in future studies.

\section{Patterns of Study Group Usage}

Qualitative results from this study suggest that the likelihood of a student utilizing a study group is affected by his or her 1) preconceptions regarding study groups and 2) actual experiences in the course. To reflect the data from this part of the study, a model was created (Figure 3 ) that represents the positive and negative factors students weigh when considering whether to use a study group as well as how the relative influ- ence of these factors may change over time (preconceptions vs. actual experiences).

Students had strong preconceptions about study groups, how they function, and what factors influence proper function. For example, we believe that students who see a benefit to studying socially start off more likely to utilize study groups than those students who prefer individual studying. Preconceptions regarding group composition were both positive and negative and were further reflected in the themes of group equity, productivity, and focus, which students believed were important to group success. Concerns about group composition have been voiced by students in other studies (Phipps et al., 2001; Lizzio and Wilson, 2005). Many students in our study believed that who is in their group is an effective predictor of group success. These findings are consistent with research that suggests students' past study group experiences influence attitudes toward future study groups (Forrest and Miller, 2003).

In addition to their preconceptions, some students' actual experiences in the biology course itself influenced their decision to use or reject study groups. During the semester, some students realized a desire for help or clarification with course content and turned to a study group. Others had a desire to do so but could not find either the time or a group. These two opposing themes of desire for help and logistical constraint suggest that students' predispositions toward study groups (either for or against) may be overcome when the semester begins and the students are immersed in the course. In many ways, a student's decision to use or not use a study group is a complex cost-benefit analysis that is based on an ever-changing matrix of his or her previous experiences using study groups and current learning needs for a course.

The four major patterns of study group usage we found in our study can be explained by our model of students' cost-benefit analyses. Students who never used study groups likely had negative preconceptions of study groups to begin with and either were not presented with a need to use them 
during the course or felt constrained by logistics. Conversely, students who always participated in study groups likely had positive preconceptions of study groups, felt they needed to clarify course material, and found a study group in their dorm. Those students who initially rejected study groups but later participated may have found a need for assistance based on their experiences in the course, although they initially had rejected the idea of joining a group or perhaps had not identified one at the beginning of the year. While we do not have specific data on why students quit using study groups, student explanations of why they chose not to form study groups suggest logistical difficulties such as lack of time or ability to meet with others may have contributed to this decision.

\section{Student Perceptions of Study Groups}

Most students in this study who participated in study groups had a positive attitude about the experience and believed study groups helped their grades, but this perception of benefit decreased throughout the semester. One possible explanation is the multiple-choice testing format of the course. Students employ different types of studying for multiplechoice exams versus short answer or essay exams (Martinez, 1999). Because students perceive multiple-choice tests as requiring large amounts of memorization (Phipps et al., 2001), they may find study groups to be less useful for this type of assessment. An alternative explanation is that student perception of the utility of study groups changed as the learning goals for the content changed. The course began with evolution and ecology and ended with the diversity of life, including the characteristics of major groups (i.e., kingdoms and phyla). The ecology/evolution portion of the class typically requires more conceptual understanding and synthesis of information, while the diversity portion tends to emphasize information that can be memorized. If students perceived this shift, their preferred study strategy may have changed through the semester. Additional studies that investigate the relationship among study group usage, learning goals, and assessment type may be helpful in understanding why student perceptions of study group usefulness declined.

\section{Implications for Practice}

Students participating in this study wanted to know how to use study groups, and research suggests that typical undergraduates do not know how (Phipps et al., 2001). It has previously been found that students often need help in using cooperative learning groups effectively; significantly greater achievement was made by students who received training in group work compared with those who received no formal training (Maloof and White, 2005). Therefore, instructors must actively facilitate the use of study groups if they want students to successfully use them. Many aspects of out-ofclass study group usage are beyond the control of instructors. For example, there is nothing an instructor can do about student preconceptions of study groups, and instructors have no direct control over study group composition in self-formed groups. However, instructors can make students aware of potential group composition problems, make suggestions on how to choose groups members who are compatible, and provide students with something on which to focus their study efforts.
Group composition can affect students' success in study groups, and research on in-class cooperative groups can possibly inform instructors how to help students form successful groups. For example, it has been noted that self-formed cooperative groups within a classroom setting tend to have problems with "slackers," or students who do not equitably participate and contribute to the group (Crowe and Hill, 2006). To mitigate this problem, and to keep more outspoken students from dominating the group, instructors could suggest that students assign themselves specific roles to play in the group (Barkley et al., 2005). For instance, students could take turns acting as facilitator, recorder, reporter, and time keeper (Tanner et al., 2003). Most importantly, instructors can stress that students choose members with whom they work well and not necessarily whom they like to hang out with.

Not knowing what to do in their study groups was a problem for a majority of students in this study. In addition, even though no assignments were explicitly given to students to complete as a group, some students reported using material generated by instructors in their study groups. This suggests that these students spontaneously organized study efforts around what they presumably perceived was important to know for the in-class exams. Instructors can help study groups organize their efforts and more efficiently utilize their time by providing students with a list of relevant concepts or topics for discussion and suggesting students study prior to meeting with their group. Another recommendation is to suggest to students that they convene study groups following individual preparation such as completing assigned readings (Light, 2001).

In addition to providing specific topical advice on group composition and study materials, instructors can also use a small amount of class time to teach students to form study groups on their own as part of a basic study skills lesson. This could be done by conducting "ice-breaker" activities in class to help students meet one another (Jensen et al., 2002). Also, instructors could model proper group function with specially designed activities during the first class period (Dinan, 2006; Wood, 2009). A small investment of class time during which instructors teach such skills at the beginning of the semester may minimize the problems students face in study groups (Gillespie et al., 2006).

\section{CONCLUSIONS}

In introductory science courses such as the one studied here, simply encouraging students to use out-of-class study groups may not have measurable learning benefits in terms of exam scores. Even so, some students felt that their participation in study groups was beneficial. This suggests that participation in these groups may have benefits outside those we measured. Students' decisions to use or reject study groups were based on their experiences in the course as well as their preconceptions of study groups. This suggests that negative preconceptions may be overcome if students are provided with a useful model of how to conduct a study group. We conclude that students require some level of guidance to successfully use out-of-class study groups. By applying lessons learned from studies of in-class cooperative groups, instructors can help students to maximize their success when advocating out-of-class study groups. 


\section{REFERENCES}

Armstrong N, Chang S, Brickman M (2007). Cooperative learning in industrial-sized biology classes. CBE Life Sci Educ 6, 163171.

Barkley EF, Cross KP, Major CH (2005). Collaborative Learning Techniques: A Handbook for College Faculty, San Francisco, CA: JosseyBass.

Burrowes PA (2003). A student-centered approach to teaching general biology that really works: Lord's constructivist model put to a test. Am Biol Teach 65, 491-502.

Corbin J, Strauss A (1990). Grounded theory research: procedures, canons, and evaluative criteria. Qual Sociol 13(1), 3-21.

Crowe M, Hill C (2006). Setting the stage for good group dynamics in semester-long projects in the sciences. J Coll Sci Teach 35(4), 3235 .

Devoe P, Niles C, Andrews N, Benjamin A, Blacklock L, Brainard A, Colombo E, Dudley B, Koinis C, Osgood M (2007). Lessons learned from a study-group pilot program for medical students perceived to be 'at risk.' Med Teach 29(2-3), 37-40.

Dinan FJ (2006). Opening day: getting started in a cooperative classroom. J Coll Sci Teach 35(4), 12-14.

Ebert-May D, Brewer C, Allred S (1997). Innovation in large lectures-teaching for active learning. Bioscience 47, 601-607.

Forrest KD, Miller RL (2003). Not another group project: why good teachers should care about bad group experiences. Teach Psychol 30, 244-246.

Gillespie D, Rosamond S, Thomas E (2006). Grouped out? Undergraduates' default strategies for participating in multiple small groups. J Gen Educ 55(2), 81-102.

Herried CF (1998). Why isn't cooperative learning used to teach science? Bioscience 48, 553-559.

Jensen M, Moore R, Hatch J (2002). Cooperative learning-part II. Cooperative group activities for the first week of class: setting the tone with group web pages. Am Biol Teach 64, 118120 .

Johnson DW, Johnson RT (1999). Learning Together and Alone: Cooperative, Competitive, and Individualistic Learning, 5th ed., Boston, MA: Allyn and Bacon.

Johnson DW, Johnson RT, Smith KA (1991). Cooperative Learning: Increasing College Faculty Instructional Productivity, ASHEERIC Higher Education Reports, No. 4. Washington, DC: George Washington University.

Johnson DW, Johnson RT, Smith KA (1998). Active Learning: Cooperation in the College Classroom, Edina, MN: Interaction Book Company.

Light RJ (2001). Making the Most of College: Students Speak Their Minds, Cambridge, MA: Harvard University Press.
Lizzio A, Wilson K (2005). Self-managed learning groups in higher education: students' perceptions of process and outcomes. Br J Educ Psychol 75, 373-390.

Maloof J, White VKB (2005). Team study training in the college biology laboratory. J Biol Educ 39(3), 120-124.

Martinez ME (1999). Cognition and the question of test item format. Educ Psychol 34(4), 207-218.

Peterson SE, Miller JA (2004). Comparing the quality of students' experiences during cooperative learning and large-group instruction. J Educ Res 97(3), 123-133.

Petress KC (2004). The benefits of group study. Education 124, 587589.

Phipps M, Phipps C, Kask S, Higgins S (2001). University students perceptions of cooperative learning: implications for administrators and instructors. J Exp Educ 24(1), 14-21.

Pukkila PJ (2004). Introducing student inquiry in large introductory genetics classes. Genetics 166, 11-18.

Seymour E, Hewitt NM (1997). Talking About Leaving: Why Undergraduates Leave the Sciences, Oxford: Westview Press.

Slavin RE (1995). Cooperative Learning: Theory, Research, and Practice, 2nd ed., Boston, MA: Allyn and Bacon.

Slavin RE (1996). Research on cooperative learning and achievement: what we know, what we need to know. Contemp Educ Psychol 21, 43-69.

Sokolove PG, Marbach-Ad G (1999). The benefits of out-of-class group study for improving student performance on exams: a comparison of outcomes in active-learning and traditional college biology classes. J Excel Coll Teach 10(3), 49-67.

Sokolove PG, Marbach-Ad G, Fusco J (2003). Student use of Internet study rooms for out-of-class group study in introductory biology. J Sci Educ Tech 12(2), 105-113.

Springer L, Stanne ME, Donovan S (1999). Effects of smallgroup learning on undergraduates in science, mathematics, engineering, and technology: a meta-analysis. Rev Educ Res 69(1), 21-51.

Tang KCC (1993). Spontaneous collaborative learning: a new dimension in student learning experience. High Educ Res Develop 12(2), 115-130.

Tanner K, Chatman LS, Allen D (2003). Approaches to cell biology teaching: cooperative learning in the science classroom-beyond students working in groups. Cell Biol Educ 2, 1-5.

Tessier J (2007). Small-group peer teaching in an introductory biology classroom. J Coll Sci Teach 36(4), 64-66.

Treisman U (1992). Studying students studying calculus: a look at the lives of minority mathematics students in college. Coll Math J 23, 362-372.

Wood BS (2009). Learning science while constructing learning teams. J Coll Sci Teach 38(5), 28-32. 